\title{
Evidence of Male Attractants for Fruit Flies in the Leaf Extract of Schinus molle
}

\section{N.K. GIKONYO ${ }^{1 *}$ AND S.A. LUX}

'Department of Pharmacology and Pharmacognosy, Faculty of Pharmacy, College of Health Sciences, University of Nairobi, P.O. Box 19676-00202, Nairobi, Kenya

'International Centre Of Insect Physiology And Ecology, P.O. Box 3077200100 Nairobi, Kenya.

\begin{abstract}
Attractiveness of odor from leaves of pepper tree (Schinus molle) to male Cerutitis rosa and $C$. capitata was evaluated in a wind-tunnel. Odor from the leaves was as attractive to male $C$. rosa as Trimedlure and more attractive to $C$. capitata males. Responses of both male and female $C$. cosyra, $C$. rosa and $C$. capitata when presented with an extract from $S$. molle leaves were also evaluated. The flies were highly activated and only males were attracted and-landed on the treated dispenser. Onset of activation was more rapid for $C$. rosa and $C$. capitata than for $C$. cosyra. Similarly, large numbers of male $C$. capitata and $C$. rosa landed on treated dispenser than $C$. cosyra. Analysis of the $S$. molle extract by gas chromatography and gas chromatography-mass spectrometry reveakd several monoterpenes and sesquiterpenes. Some of the terpenoids or their blend may constitute a male attractant (parapheromone) for $C$. capitata, $C$. rosa and possibly other fruit flies attracted to Trimedlure.
\end{abstract}

Key words: Fruit fly, Ceratitis capitata. C. cosyra, C. rosa, parapheromone. Schinus molle, pepper tree.

\section{INTRODUCTION}

Fruit flies are very destructive pests of many forms of horticulture in the tropical and temperate world. Expensive monitoring ano control programs. including use of the environmentally harmful pesticides are used to counter the scourge. Fruit flies are polyphagus with an ever-expanding host range, have long life and a high capacity for dispersal. making their control difficult. Fruit flies belong to the family Tephritidae, which has about 500 genera and 4000 species. The genus Ceratitis contains about 65 species found in tropical and southern Africa [1], among which the Mediterranean fruit fly Ceratitis capitata Wiedemann, the Mango fruit fly $C$. cosyra Walker. and the Natal fruit fly Ceratitis rosa Karsch, are the most destructive. $C$. capitata is a pest of global concern and attacks about 300 plant species. Ceratitis rosa and C. cosyra are reported to attack over 50 and 7 commercial and wild fruits, respectively $[1-5]$.

Parapheromones are chemicals that elicit behavioral responses similar to semiochemicals, but are not naturally used in intra-specific or interspecific communication. All available parapheromones have been discovered from plants by chance or through trial and error of synthetic compounds. Parapheromones identified so far for tephritid fruit flies elicit a behavioral response similar to pheromones and they specifically attract males [6-11]. Parapheromones that attract some male Ceratitis species especially $C$. capitata and $C$. rosa but not $C$. cosyra. include the synthetic compound "Siglure" (sec-butil-6-methyl-3cyciohexene carboxylate). from which other attractânts. "Medlure" (sec-butyl-4 (or 5)-chloro2-methylcyclohexane carboxylate) and "Trimedlure" ( $t$-butyl-4 (or 5)-chloro-2-methylcyclohexane carboxylate) were synthesized by hydrohalogenation $[6.10]$. Terpineol acetate occurs in plants and is attractive to male $C$. capitata. C. rosa and C. cosyra. $\alpha$-Copaene and its isomer $\alpha$-ylangene. isolated from angelica root oil. are male attractants for $C$. rosa $[6,12]$. Parapheromones have been used with some success. in monitoring and control programmes of fruit flies. but not for $C$. cosyra and C. rosa $[13$ 16]. The African fruit flies $C$. capitata, $C$. cosyra and $C$. rosa are highly polyphagus and with the growing fruit export-industry, there is an increase in the risk of translocation to other parts of the world. There is therefore an urgent need to have more attractants and especially parapheromones 
that are easily available for fruit fly monitoring and control.

Crushed leaves of the pepper tree Schinus molle (Anacardiaceae) produce a spicy, aromatic scent, typical of unripe mango fruits. Since immature mango fruits were previously shown to attract wild mango fruit flies $C$. cosyra [17], the aroma of $S$. molle prompted the authors to carry out the study described here. In this study, we report the responses of $C$. capitata, $C$. cosyra and $C$. rosa to $S$. molle leaves and its oil in a wind-tunnel and in rearing cages. The chemical constituents of the oil and construction of the wind-tunnel are described.

\section{MATERIALS AND METHOD}

\section{Flies}

The fruit flies Ceratitis cosıra. $C$. capitata and $C$. rosa were obtained from insectaries at the International Centre of Insect Physiology and Ecology (ICIPE), where they were maintained under 12:12 normal photoperiod. $29 \pm 1{ }^{\circ} \mathrm{C}$ and 65 $\pm 5 \% \mathrm{r}$.h. The flies were maintained on artificial diet in cages of dimension $70 \mathrm{~cm} \times 60 \mathrm{~cm} \times 35 \mathrm{~cm}$ or $50 \mathrm{~cm} \times 50 \mathrm{~cm} \times 50 \mathrm{~cm}$. For wind-tunnel experiments. 3-week old flies were placed in release cages $(15 \mathrm{~cm} \times 15 \mathrm{~cm} \times 20 \mathrm{~cm})$ made of Perspex and kept in a bioassay room maintained as above. The flies were not presented with food or drink until experiments were carried out the following day.

\section{Extraction of Oil from Leaves of Schinus molle}

Fresh leaves of pepper tree were chopped into smaller pieces and then extracted using $n$-hexane for eight hours. The extract was decanted, filtered and then dried using anhydrous magnesium sulphate. Half of the solvent was removed in a rotary evaporator and the rest using a gentle stream of nitrogen, yielding an aromatic-scented oil.

\section{The Wind-Tunnel}

The wind-tunnel was made of an aluminum frame $(120 \mathrm{~cm} \times 70 \mathrm{~cm} \times 70 \mathrm{~cm}$ ), with floor made from aluminum sheet, while the top and sides were made of transparent glass. Doors made of an aluminum frame and wire mesh were fixed on the two ends of the tunnel. Air current (wind) was generated from computer CPU cooler fans $(12 \mathrm{~V}$. $0.08 \mathrm{~A}$ ) fixed on an aluminum sheet that was fitted on the odor-dispensing box (ODB). The ODB was made of an aluminum frame $(46 \mathrm{~cm} \times 46 \mathrm{~cm})$ on which an aluminum sheet was fitted. The aluminum sheet was divided into 16 equal square segments $(11.5 \mathrm{~cm} \times 11.5 \mathrm{~cm})$ and holes $(5 \mathrm{~cm}$. diameter) drilled in the middle of each segment. Each of these holes was covered with a fine brass wire mesh. Aluminum rods $(10 \mathrm{~cm}$ in length and $1 \mathrm{~cm}$ diameter) were riveted on every corner of each square segment so that a glass tube $(11 \mathrm{~cm}$ diameter, $11.5 \mathrm{~cm}$ height. Bolosilicate) could be inserted in between. The ODB could therefore hold 16 glass tubes (and hence samples) each occupying $4.5 \%$ of the dispensing surface. The aluminum sheet containing the fans fitted to the backside of the ODB via movable hooks such that each fan blew air through the holes into the middle of the glass tubes (Figure 1). Power was supplied to the fans via an AC-DC variable transformer $(1.5-12.0 \mathrm{~V})$. Varying voltage output from the transformer regulated wind speed. The bioassay, apparatus was illuminated lengthwise from both sides and top using fluorescent tubes (36W) having daylight intensity. Humidity in the tunnel was provided from pumice stones soaked in water and placed in petri dishes. Resting objects (for flies). with stem made from thin metal rods and leaves of paper or metal-sheet, were placed inside the tunnel.

\section{Wind-Tunnel Bioassay}

The bioassay room was maintained at $29 \pm 1{ }^{\circ} \mathrm{C}$ and $65 \pm 5 \%$ r.h. under normal photoperiod. Flies were introduced into the wind tunnel by placing the release cage on an aluminum rack $(17 \mathrm{~cm}$ in height) placed at the downwind end (Fig 1). A single test sample, "Trimedlure" (TML) or leaves of pepper tree, was placed inside one glass tube and the ODB placed on the outer side of the upwind end of the tunnel. "Trimedlure" was obtained in a commercial dispensing plug (AgriSense, Fresno, CA, USA). This plug was placed inside a $15 \mathrm{ml}$ Teflon centrifuge tube and closed with a $2 \mathrm{~cm}$ diameter cap. Three holes, each of about $1 \mathrm{~mm}$ in diameter, were drilled on the cap so as to reduce the amount 


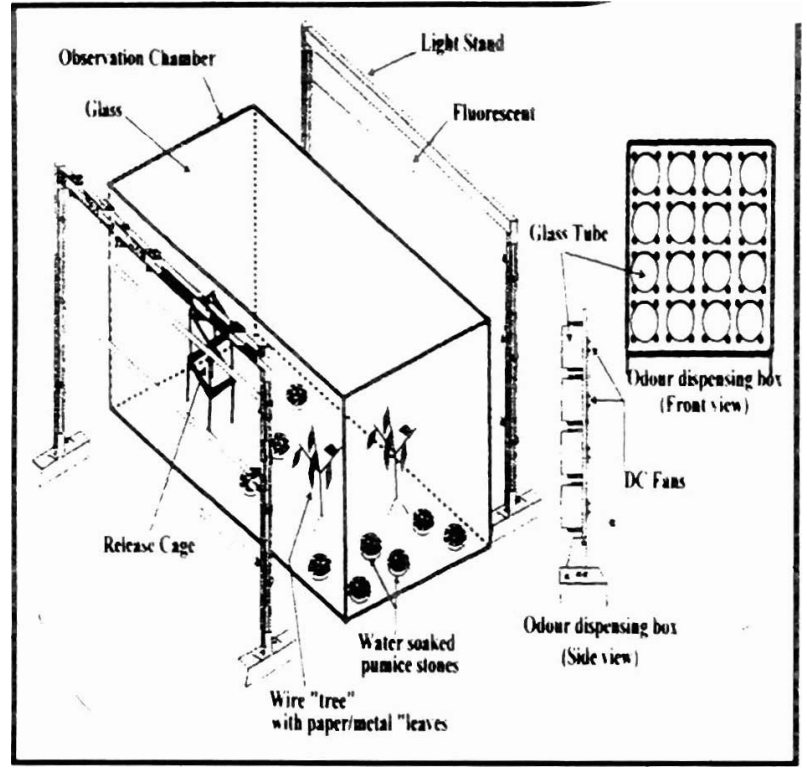

Figure 1: The Wind-tunnel

of TML released. Fans were put on (at 12V) for about $10 \mathrm{~min}$ before the release cage was opened. The behavior of flies was observed continuously but scoring was done at intervals of five minutes. for a period of one hour.

\section{Bioassay in Rearing Cages}

Oil of $S$. molle $(10 \mu \mathrm{l})$ was carefully pipetted onto a cotton wick (2 cm long and $1 \mathrm{~cm}$ in diameter) dispenser hooked at the end of a stainless steel wire stand $(30 \mathrm{~cm}$ tall). For the control, a wick of similar dimensions was placed on a separate wire stand but nothing was added. The treated and control dispensers were carefully inserted into a rearing cage, care being taken not to place them close to food source, oviposition substrates or resting objects. The distance between the control and treated dispensers was about $20 \mathrm{~cm}$. Experiments were conducted at between 14:45 and 15:30 h on the four age groups of flies (1-, 2-. 3- \& 4-week old) starting with the youngest. Observations made within a period of four minutes included initiation of agitation or excitement (activation) and its end, the sex and number of flies landing on the dispenser. Enhanced walking, short hops and flight, characterized activation of the flies. When the activation was associated with enhanced walking and occasional hops, it was scored as low, while short hops and a few flights were scored as mild.
When flies were mainly flying, activation was scored as high.

\section{Gas chromatography-Mass Spectrometry}

Gas chromatographic (GC) analysis was conducted on a Hewlett Packard (HP) (Avondale, PA, USA) model 5890 Series II gas chromatograph equipped with a splitless capillary injector system, a flame ionization detector (FID) and an HP 3396 Series II integrator. A fused silica capillary column, $50 \mathrm{~m} \times 0.2 \mathrm{~mm}$ internal diameter (i.d.) coated with cross-linked methyl silicone gum $(0.11 \mu \mathrm{m}$ film thickness) HP was used with nitrogen as carrier gas. The oven temperature was kept isothermal at $40{ }^{\circ} \mathrm{C}$ for 10 min following injection of a sample and then programmed at $5{ }^{\circ} \mathrm{C} / \mathrm{min}$ to $280{ }^{\circ} \mathrm{C}$ where it was held for $20 \mathrm{~min}$. Schimus molle oil was diluted in redistilled $n$-hexane and 1-2 $\mu \mathrm{l}$ of the solution injected in the splitless mode with a $45 \mathrm{sec}$ delay before injection purging. The injector and detector temperatures were held at $250{ }^{\circ} \mathrm{C}$ and $280{ }^{\circ} \mathrm{C}$. respectively:

\section{Gas Chromatography-Mass Spectrometry}

Gas chromatography-mass spectrometry (GC-MS) analysis was carried out on a VG platform II (Fisons instruments) mass spectrometer coupled to series 8000 gas chromatograph; model 8060 MS II (Fisons instruments. Cheshire. UK). The GC column and oven temperature programming were the same as those described for the GC analysis. Compounds in $S$. molle oil were identified from their mass spectra and by comparing with a computerized library of mass spectra. The compounds were confirmed by GC co-injection of authentic compounds and the oil.

\section{RESULTS AND DISCUSSIONS}

Attractiveness of Trimedlure (TML) to male $C$. capitata, $C$. rosa and $C$. cosyra in the wind-tunnel was evaluated with a view to standardize the tunnel. Table 1B shows that $70 \%$ of $C$. rosa and $4.2 \%$ of $C$. capitata males that landed on upwind screen, were attracted to the Trimedlure dispenser. From the low proportion (4.2\%) of $C$. cosyra attracted to TML dispenser, it is clear that TML is not a lure for $C$. cosyra males. The attractiveness 
of TML to $C$. rosa and $C$. capitata and not $C$. cosyra has been reported before $[1,6,10]$ and therefore the wind-tunnel is sufficiently sensitive for testing olfactory stimuli. Table 1 shows that odor from leaves of the pepper tree (a non-host plant) is highly attractive to both $C$. capitata and $C$. rosa. Odor from leaves of the pepper tree was as attractive to male $C$. rosa as TML and more attractive to $C$. capitata males. This indicates that the pepper tree leaves have potent attractants for these fruit flies.

Flies presented with oil of $S$. molle responded by enhanced walking, short hops and flight. These fruit flies are normally quiescent unless during courtship. Onset of activation was rapid for both $C$. rosa and $C$. capitata and lasted the entire test period of four minutes on all age groups (Table 2 ). For the 1-and 2-week old C. capitata and C. rosa, flies were highly activated within 3 - and 5 - sec respectively. Wheréas 3-week old $C$. rosa remained highly activated throughout observation period, $C$. capitata was only mildly activated. In contrast, onset of activation for 1 - week old $C$. cosyra took $40 \mathrm{sec}$ and lasted for only $50 \mathrm{sec}$. Onset of activation for 2- and 3-week old $C$. cosyra was as rapid as for $C$. rosa and $C$. capitata. However, 3-week old $C$. cosyra flies were not active by end of the experiment and neither were 4-week old activated. Aged (4-week old) C. rosa and $C$. capitata were only mildly activated. Generally, activation was highest for young $C$. rosa and $C$. capitata and diminished with age, while activation of $C$. cosyra peaked on the second week.

Activated flies that-were attracted to the odor source preferentially landed on the treated dispenser (Table 2). In all the three species, only males landed on dispensers and they were seen to probe the treated surface with proboscis. Once landed, the flies would remain on one spot until disturbed by other flies landing near or on them. This was the case for $C$. rosa and $C$. capitata struggling for space on the dispenser. For $C$. capitata and $C$. rosa, the number of males landing was highest for the 1- and 2-week old and lowest for the 4-week old flies. The 1- and 2-week old $C$. capitata males were more attracted and landed on treated dispenser than $C$. rosa. However. $C$. rosa males remained attracted and landed throughout the age group. The number of $C$. capitata males landing on the treated dispenser increased with time from start of experiment while for C. rosa, the number landing peaked on the second minute and reduced by the end of the experiment. Although a few 2-week old males of $C$. cosyra landed on the treated dispenser, the odor from $S$. molle leaf extract did not appear to be attractive to this species. This suggested that the oil from leaves of $S$. molle contains attractants (parapheromones) for those fruit flies attracted to TML. Other plant extracts that have been shown to attract fruit flies of Bactrocera and Ceratitis species include, citronella oil [6], huon pine oil [18], tulsi plant (Ocimum sanctum), flowers of canon ball tree (Couroupita guianensis) and flower spike of Spathiphyllum candicum $[7,19$, 20].

Compounds identified from the extract of $S$. molle leaves were monoterpenoids and sesquiterpenoids. Monoterpenoids included ocimene, camphene, $\alpha$ pinene, $\beta$-pinene, $\beta$-myrcene, $\alpha$-phellandrene, 3 carene, limonene, $\gamma$-terpinene and terpinolene (Table 3). Sesquiterpenoids included $\alpha$-copaene, isocaryophyllene, $\alpha$-cubebene, $\alpha$-caryophyllene, germacrene- $B$ and $\alpha$-farnesene. The major compounds in the oil were limonene $(23 \%), \alpha$ phellandrene (16\%), germacrene-B $(8 \%)$ and camphene $(5 \%)$. (E, E)- $\alpha$-Farnesene has been isolated from ylang-ylang oil [21] and is a component of male pheromone of $C$. capitata $[22$ - 24]. Interestingly, $\alpha$-farnesene was also shown to attract gravid female Dacus tryoni Froggat [25]. $\alpha$-Copaene that was previously identified from volatile odor of mango and marula fruits [17] is a male attractant for $C$. rosa and $C$. capitata [26]. Some of the individual terpenoids or their blend may constitute a cheap parapheromone for $C$. capitata, $C$. rosa and other flies attracted by TML. Furthermore, the pepper tree grows very easily and fast in the tropics and subtropics although it may be a potentially good source of the parapheromone. However, a preliminary field trapping of $C$. capitata in a coffee plantation using $S$. molle oil has not been successful. This suggests that the $S$. molle oil may need further processing to be effective as a long-range parapheromone in the field. 
31 Gikonyo and Lux

East Cent. Afr. J. Pharm. Sci. 7(2)

Table 1: Responses of Ceratitis males to leaves of pepper tree and Trimedlure in a wind-tunnel

\begin{tabular}{|c|c|c|c|c|c|c|}
\hline Test sample & $\mathbf{N}$ & Species & $\begin{array}{l}\text { Frequency } \\
\text { of landing } \\
\text { on upwind- } \\
\text { screen }\end{array}$ & $\begin{array}{l}\text { Frequency of } \\
\text { hovering and } \\
\text { landing on } \\
\text { target }\end{array}$ & $\begin{array}{l}\text { Frequency of } \\
\text { landing } \\
\text { target }\end{array}$ & $\begin{array}{l}\% \text { of flies (on } \\
\text { upwind screen) } \\
\text { landing on target }\end{array}$ \\
\hline \multirow[t]{2}{*}{ Pepper tree leaves } & 50 & C. capitata & 33 & 57 & 23 & 69.7 \\
\hline & 46 & C. rosa & 23 & 22 & 16 & 69.6 \\
\hline \multirow[t]{6}{*}{ Trimedlure } & 46 & C. capitata & 31 & 23 & 13 & 41.9 \\
\hline & & Control & 0 & 0 & 0 & - \\
\hline & 50 & C. rosa & 165 & 140 & 115 & 69.7 \\
\hline & & Control & 0 & 0 & 0 & \\
\hline & 45 & C. cosyra & 24 & 1 & 1 & 4.2 \\
\hline & & Control & 0 & 0 & 0 & - \\
\hline
\end{tabular}

Table 2: Responses of Ceratitis species to oil from leaves of Schinus molle in rearing cages

\begin{tabular}{|c|c|c|c|c|c|c|c|c|c|c|}
\hline \multirow{3}{*}{$\begin{array}{l}\text { Age of flies } \\
\text { (weeks) }\end{array}$} & \multirow{2}{*}{\multicolumn{3}{|c|}{$\begin{array}{l}\text { ACTIVATION } \\
\text { (secs) }\end{array}$}} & \multicolumn{7}{|c|}{ NUMBER OF FLIES LANDING ON TARGET } \\
\hline & & & & \multicolumn{3}{|c|}{ C. cosir $a$} & \multicolumn{2}{|c|}{ C. rosa } & \multicolumn{2}{|c|}{ C.capitata } \\
\hline & C. cosyra & C. rosas & C. capitata & $\begin{array}{l}\text { Time* } \\
\text { (mins) }\end{array}$ & $\mathbf{T}$ & C & $\mathrm{T}$ & C & $\mathrm{T}$ & C \\
\hline \multirow[t]{3}{*}{1} & $I=40(\mathrm{H})$ & $\mathrm{I}=5(\mathrm{H})$ & $\mathrm{I}=3(\mathrm{H})$ & 1 & 0 & 0 & 37 & 1 & 54 & 5 \\
\hline & $E=90(N)$ & $E=240(H)$ & $E=240(H)$ & 2 & 0 & 0 & 41 & 2 & 62 & 1 \\
\hline & & & & 4 & 0 & 0 & 31 & 1 & 95 & 0 \\
\hline \multirow[t]{3}{*}{2} & $I=6(\mathrm{H})$ & $I=5(H)$ & $I=3(\mathrm{H}$ & 1 & 3 & 1 & 33 & 1 & 33 & 1 \\
\hline & $E=240(H)$ & $E=240(H)$ & $E=240(H)$ & 2 & 6 & 0 & 41 & 7 & 57 & 0 \\
\hline & & & & 4 & 3 & 0 & 24 & 3 & 52 & 1 \\
\hline \multirow[t]{3}{*}{3} & $\mathrm{I}=7(\mathrm{M})$ & $I=8(H)$ & $\mathrm{I}=11(\mathrm{M})$ & 1 & 0 & 0 & 27 & 0 & 5 & 0 \\
\hline & $E=210(N)$ & $E=240(H)$ & $\mathrm{E}=240(\mathrm{M})$ & 2 & 0 & 0 & 33 & 0 & 13 & 0 \\
\hline & & & & 4 & 4 & 0 & 26 & 0 & 17 & 0 \\
\hline \multirow[t]{3}{*}{4} & $\mathrm{I}=240 \mathrm{~N}$ & $\mathrm{I}=9(\mathrm{M})$ & $\mathrm{I}=15(\mathrm{M})$ & 1 & 0 & 0 & 17 & 0 & 4 & 0 \\
\hline & & $E=240(L)$ & $E=240(\mathrm{~L})$ & 2 & 0 & 0 & 23 & 0 & 12 & 1 \\
\hline & & & & 4 & 0 & 0 & 19 & 0 & 15 & 0 \\
\hline
\end{tabular}

I: Onset of activation. E: End of activation or activity at end of observation period. H: High activation. M: Mild activation. L: Low activation. N: No activation. T: Test. C: Control

*: Experimental time. 
Table 3: Compounds and their percentages, detected in the oil from Schinus molle leaves.

\begin{tabular}{clrclc}
\hline Peak number & Compound & Percentage & Peak number & Compound & Percentage \\
\hline 1 & Ocimene & 2.88 & 9 & $\gamma$-Terpinene & 0.15 \\
2 & Camphene & 5.48 & 10 & Terpinolene & 0.20 \\
3 & $\alpha$-Pinene & 0.56 & 11 & $\alpha$-Copaene & 0.43 \\
4 & $\beta$-Pinene & 2.66 & 12 & Isocryophyllene & 1.63 \\
5 & $\beta$-Myrcene & 2.59 & 13 & $\alpha$-Cubebene & 1.04 \\
6 & $\alpha$-Phellandrene & 16.20 & 14 & $\alpha$-Caryophyllene & 3.96 \\
7 & 3 -Carene & 1.34 & 15 & Germacrene-B & 7.61 \\
8 & Limonene & 23.34 & 16 & $\alpha$-Farnesene & 3.66 \\
\hline
\end{tabular}

Peak number indicates the order of elution from GC column

\section{ACKNOWLEDGEMENTS}

We thank P.N. Onkoba. O.W. Kaye and all the personnel of the fruit fly insectaries of ICIPE. A.N. Muturi. Faculty of Pharmacy. University of Nairobi. L.K. Murungi. Department of Horticulture. Jomo Kenyatta University of Agriculture and Technology for their technical assistance. This research was funded by International Fund for Agricultural Development (IFAD) to whom we are most thankful.

\section{REFERENCES}

[1] M. White and M.M. Elson-Harris. Fruit flies of economic significance: Their identification and Bionomics. $\mathrm{CAB}$ international. Wallingford. Oxon. UK. (1994), p 601.

[2] E.J. Harris in A.S. Robinson and G. Hooper (eds). Pest status; Hawaiian Island and North America. World Crop Pests, Fruit flies: Their biology, natural enemies and control. Elsevier, Amsterdam. 3A (1989), p 73-81.

[3] F.M. Eskafi and R.T. Cunningham. Florida Entomologist. 70 (1987) 116123.

[4] D.L. Hancock. Trans. of the Zimbabwe Sci. Assoc. 63 (1987) 47-57.

[5] T.K. Mukiama and J.K. Muraya. Insect Sci. Applic. 15 (1994) 155-159.
[6] R.T. Cunningham in A.S. Robinson and G. Hooper (eds). Parapheromones. World Crop Pests. Fruit flies: Their biology. natural enemies and control. Elsevier. Amsterdam. 3A (1989), p 221-230.

[7] A.H. Shah and R.C. Patel. Current Science. 45 (1976) 313-314.

[8] R.A.I. Drew. J. of the Australian Entomol. Soc. 13 (1974) 267-270.

[9] R.A.I. Drew and G.H.S. Hooper. J. of the Australian Entomol. Soc. 20 (1981) 201205.

[10] M.T. Fletcher and W. Kitching. Chemical Reviews. 95 (1995) 789-828.

[11] D.L. Hancock. The Zimbabwe Science News. 19 (1985) No 9/10.

[12] M. Beroza and N. Green (eds). Materials tested as insect attractants. United States Department of Agriculture, Agriculture Handbooks. No. 239 (1963) pp 148.

[13] L.F. Steiner, W.C. Mitchell, E.J. Harris, T.T. Kozuma and M.S. Fujimoto. J. Econ. Entomol. 58 (1965) 961-964.

[14] M.A. Bateman, V. Insunza and P. Arretz. FAO Plant Protection Bulletin. 21 (1973) 114.

[15] A. Manrakhan and N.S. Rice. Seasonal profiles in production, fruit fly 
populations and fruit fly damage in mangoes in Mauritius. Third annual meeting of Agricultural Scientists, MSIRI, Reduit, Mauritius. 21-22 Oct. 1999.

[16] G. Haniotakis, M. Kozyrakis, T. Fitsakis and A. Antonidaki. J. Econ. Entomol. 84 (1991) 564-569.

[17] N.K. Gikonyo, S.A. Lux and P.S. Nemeye. East Cent. Afr. J. Pharm. Sci. 6 (2003) 3-8.

[18] R.A.I. Drew in R.A.I. Drew, G.H.S. Hooper and M.A. Bateman (eds). Fruit fly collecting: Economic fruit flies of the South Pacific Region. $2^{\text {nd }}$ ed. Brisbane. IV (1982) p 129-139.

[19] J.A. Lewis, C.F. Moore, M.T. Fletcher. R.A.I. Drew and W. Kitching. Phytochemistry. 27 (1988) 2755-2757.

[20] H.S. Yong. Nature Malaysiana. 15 (1990) 92-97.
[21] E.B. Jang, D.M. Light, R.G. Binder, R.A. Flath and L.A. Carvalho. J. Chem. Ecol. 20 (1994) 9-20.

[22] E.B. Jang, D.M. Light, R.A. Flath, J.T. Nagata and T.R. Mon. Entomol. Exp. Applic. 50 (1989) 7-19.

[23] R.R. Heath, P.J. Landolt, J.H. Tumlinson, D.L. Chambers, R.E. Murphy, R.E. Doolittle, B.D. Dueben, J. Sivinski and C.O. Calkins. J. Chem. Ecol. 17 (1991) 1925-1940.

[24] R.A. Flath, E.B. Jang, D.M. Light. T.R. Mon, L.A. Carvalho, R.G. Binder and J.O. John. J. Agric. Food Chem. 41 (1993) 830-837.

[25] C.H. Eisemann and M.J. Rice. Entomol. Exp. Appl. 62 (1992) 125-130.

[26] R.A. Flath. R.T. Cunningham. T.R. Mon and J.O. John. J. Chem. Ecol. 20 (1994) 2595-2609. 